\title{
Geological Terrain Mapping using Geographic Information System (GIS) and Drone Photogrammetry
}

\section{Muhammad Afiq Abdul Kahar ${ }^{1}$, Hamzah Hussin ${ }^{1 *}$, Aziman Madun ${ }^{2,3}$, Mohd Khaidir Abu Talib ${ }^{2}$, Saiful Wazlan Wahab ${ }^{4}$}

${ }^{1}$ Geoscience Department, Faculty of Earth Science,

University Malaysia Kelantan, 17600 Jeli, Kelantan, MALAYSIA

${ }^{2}$ Faculty of Civil Engineering and Built Environment,

Universiti Tun Hussein Onn of Malaysia, 86400 Parit Raja, Johor, MALAYSIA

${ }^{3}$ Preston GeoCEM Sdn Bhd, 33A, Jalan Universiti 4, Taman Universiti, 86400 Parit Raja, Johor, MALAYSIA

${ }^{4}$ Department of Survey and Mapping Malaysia,

Wisma JUPEM, Jalan Sultan Yahya Petra, 50578 Kuala Lumpur, MALAYSIA

*Corresponding Author

DOI: https://doi.org/10.30880/jsue.2021.01.01.001

Received 24 August 2021; Accepted 11 October 2021; Available online 16 December 2021

\begin{abstract}
The research area was conducted within the Bukit Persekutuan, Kuala Lumpur, and it was located at the latitude $3^{\circ} 8^{\prime} 32.93 " \mathrm{~N}$ and longitude $101^{\circ} 40^{\prime} 32.80^{\prime \prime} \mathrm{E}$. The researcher carried out geological terrain mapping to evaluate the research area in accordance with the geological terrain classification attributes of each thematic map produced, namely, Terrain map, slope gradient map, erosion, and instability map, as well as construction suitability map. The occurrence of landslide events within the research area becomes a major contributing factor to thoroughly conducting an investigation by field mapping and analysing using the Geographic Information System (GIS) technology. The application of Geographic Information System (GIS) and drone photogrammetry images play an essential role to analyze and process the data, thus, generate the thematic maps. The research area indicates that about $79.11 \%$ of the overall area was not appreciable with erosion, $8.58 \%$ contribute to the erosion, $11.00 \%$ of recent general instability, and $2.97 \%$ represent a landslide event. The suitability for development mapping illustrated Class I (23.40), Class II (36.37\%), Class III (26.39\%), and Class IV (15.50\%) where it can be referred to the construction suitability classification system, the suitability for development was high in class I, moderate in class II, low in class III and not suitable in class IV.
\end{abstract}

Keywords: Geological terrain mapping, landslide, GIS, drone photogrammetry

\section{Introduction}

The geological hazard assessment such as landslide was carried out in Malaysia yearly as it poses a threat to life and the environment. The evidence of erosion, instability and any other slope failure indicates mitigation measures were needed to provide information of the regional conditions through the geologists and geotechnical engineers towards the local land use development planning [5]. The information collected was necessary for the research area regarding the development of the foundation, layout plans preparation, infrastructure design, and the construction methodology. The inclusive site investigation was implemented to obtain geological and geotechnical aspects that contribute to the landslide event. The data afterwards was evaluated for further justification and mitigation actions. 
The terrain appraisal systems were employed to identify diverse activities of the research area based on the geological terrain classification attributes provided by the Minerals and Geoscience Department Malaysia (JMG) in 2002. As a result, there were numerous terrain appraisal systems [2] following the different purposes. The geological terrain mapping guidelines programme developed by the Mineral and Geoscience Department Malaysia (JMG) was a derivation and modified version of the Geotechnical Engineering Office in Hong Kong [3]. Afterwards, such an approach was implemented under the act, planning guidelines for Development Planning on Hills and Highlands [6], Local Authorities and State Authorities [10], and the standards of National Slope Master Plan 2009-2023 [4] related to slope repair projects within the research area.

\section{Methodology}

\subsection{Field Mapping}

The study involved surface investigation such as for development studies [9] through detailed geological mapping on the failed slope, notably in the failure scarp. The geological mapping was conducted in a walkover survey and covered areas accessible by foot. The pertinent geological features such as lithological types, discontinuities, weathering stage, and the existing and anticipated geodynamic features were recorded in a map. In addition, photographs of the relevant geological and geodynamic features were captured for the record. In this study, the degree of weathering for the rock masses and the discontinuity features and field estimation of the rock strength were described using the classification scheme of ISRM in 1981 [11].

Table 1 - Weathering classification by ISRM (1981)

\begin{tabular}{|c|c|c|}
\hline Grade & Grade & Diagnostic Features \\
\hline Fresh & I & $\begin{array}{l}\text { No visible sign of decomposition or discoloration. } \\
\text { Rings under hammer impact. }\end{array}$ \\
\hline Slightly Weathered & II & Slight discoloration inwards from open fractures. \\
\hline Moderately Weathered & III & $\begin{array}{l}\text { Discolored throughout. Weaker minerals such as feldspar } \\
\text { discomposed. Strength somewhat less than fresh rock but cores } \\
\text { cannot be broken by hand or scraped by knife. Texture preserved. }\end{array}$ \\
\hline Highly Weathered & IV & $\begin{array}{l}\text { Most minerals somewhat decomposed. Specimens can be broken } \\
\text { by hand with effort or shaved with knife. Core stones present in } \\
\text { rock mass. Texture becoming indistinct but fabric preserved. }\end{array}$ \\
\hline Completely Weathered & $\mathrm{V}$ & $\begin{array}{l}\text { Mineral decomposed to soil but fabric and structure preserved } \\
\text { (Saprolite). Specimens easily crumbled or penetrated }\end{array}$ \\
\hline Residual Soil & VI & $\begin{array}{l}\text { Advanced state of decomposition resulting in plastic soils. Rock } \\
\text { fabric and structure completely destroyed. Large volume change. }\end{array}$ \\
\hline
\end{tabular}

\subsection{Geological Terrain Mapping}

The methodology applied by the Minerals and Geoscience Department Malaysia involves the assessment of four main attributes, namely the Slope Gradient, Terrain, Activity, and Erosion and Instability [7]. However, a fifth attribute, i.e., the cover/vegetation on the hill slopes, was also mapped [8]. The types and degree of erosion/instability on the hill slopes were correlated with the fifth attribute.

Polygons were defined based on the attributes mentioned earlier to reflect on the terrain's steepness, the morphology of the slope, the activities conducted on the slope, and the degree of erosion or instability on the slope [2]. Field inspection surveys undertook the geological terrain mapping to evaluate the accessibility, location of prominent reference points, drainage [1] and familiarization with the general geomorphology of the area. The preliminary study of geological map and topography map was required to locate zones of instability (if any), including recent and relict landslide scars, areas with prominent erosion and areas with soil creep. Other than that, to understand the morphology, activity, and vegetation cover, prepare a base map of the research area based on the topography survey plan. Besides, it was required to include a slope gradient plan generation using digital terrain modelling software such as ArcGIS. This plan was used as a basis for field mapping by undertaking a field survey through assessing the five attributes and plotting them into the polygons. The polygons were digitized and analyzed to develop the following maps: Geological Terrain, Classification Map, and Construction Suitability Map. Moreover, it was required to undertake a field check on the finished products and redrawing to re-analyses, amend the polygons, and produce the finalized plan if necessary. 


\section{Research Area}

The area of the project site was $12,000 \mathrm{~m} 2$. The research area and a drone orthomosaic are shown in Figure 1.
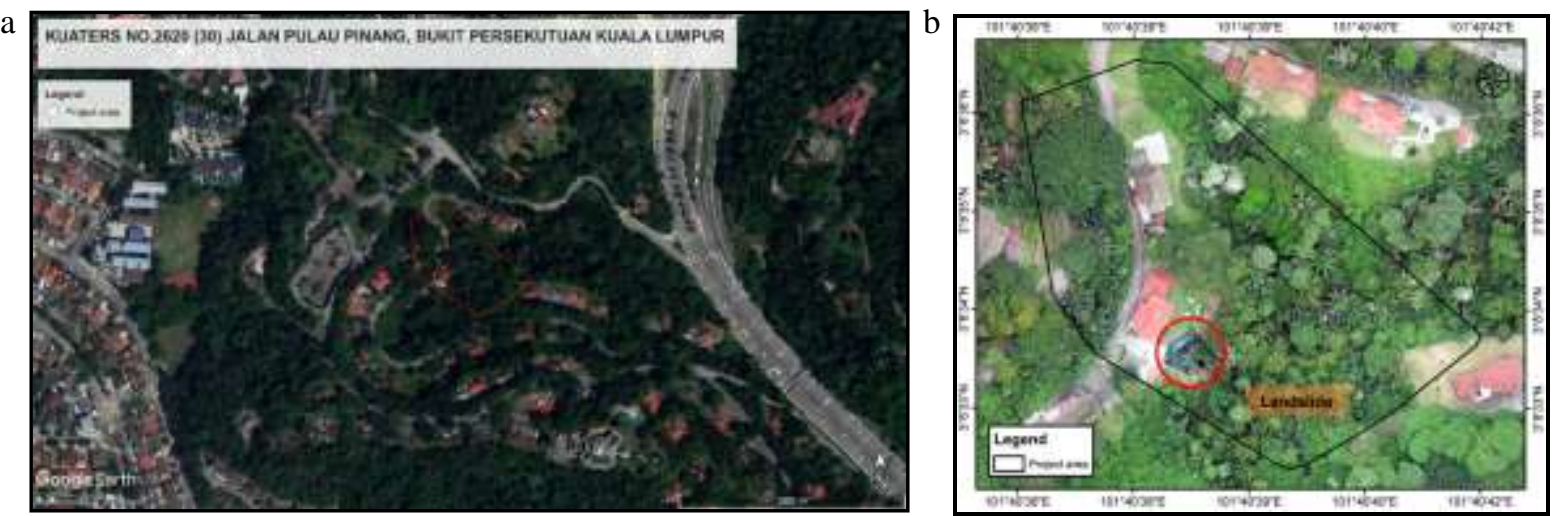

Fig. 1 - (a) Satellite image view of the project site, located in Kuaters No.2620 (30) Jalan Pulau Pinang, Bukit Persekutuan Kuala Lumpur; (b) Drone orthomosaic viewed of the research area

\section{The Geology and Site Condition of The Research Area}

The site's geology consists of Carboniferous to Permian Kenny Hill Formation, as shown in the Geological Map of Peninsular Malaysia (Figure 2) by the Geological Society of Malaysia (2008). The Kenny Hill Formation was exposed in several places, especially towards the south of Kuala Lumpur, from Petaling Jaya and Puchong to Kajang and Putrajaya. Within the research area, the weathered foliated phyllite was exposed, as shown in Figure 3. The phyllite rock mass varies in weathering grades from highly weathered to residual soil (grade VI-VI). The colour of weathered phyllite varies from light yellow to reddish-brown due to high iron oxide contents.

Weathering grade VI and V was generally weak to extremely weak rocks, while Grade VI was residual soil that consisted of clayey silt and silty clay. In Grade VI and V, the original rock fabrics and relict structures (e.g., foliation and joints) were still recognizable, and the orientation of the relict structures largely governs their geomechanical behaviour. The dip direction of phyllite foliation at $170^{\circ}$ and dip angle $20^{\circ}$. Field observation at the drainage system shows water continuously flows. The stone pitching wall at the toe of the slope was damp due to leakage of the buried water pipe at the top slope. Two locations have been identified experiencing leakage problems, as shown in Figure 5. The field observation of water flow is shown in Figure 4 and Figure 5. It was also indicating the pipe leakage at the top of the slope near the landslide. The topography of the project site area was in the range of undulating to slightly hilly. Topography height ranges from $48-74 \mathrm{~m}$. The sites' elevation increases towards the northwest, dominated by undulating terrain towards the elevation within the 48-53m and surrounded by vegetation, as shown in Figure 6 .

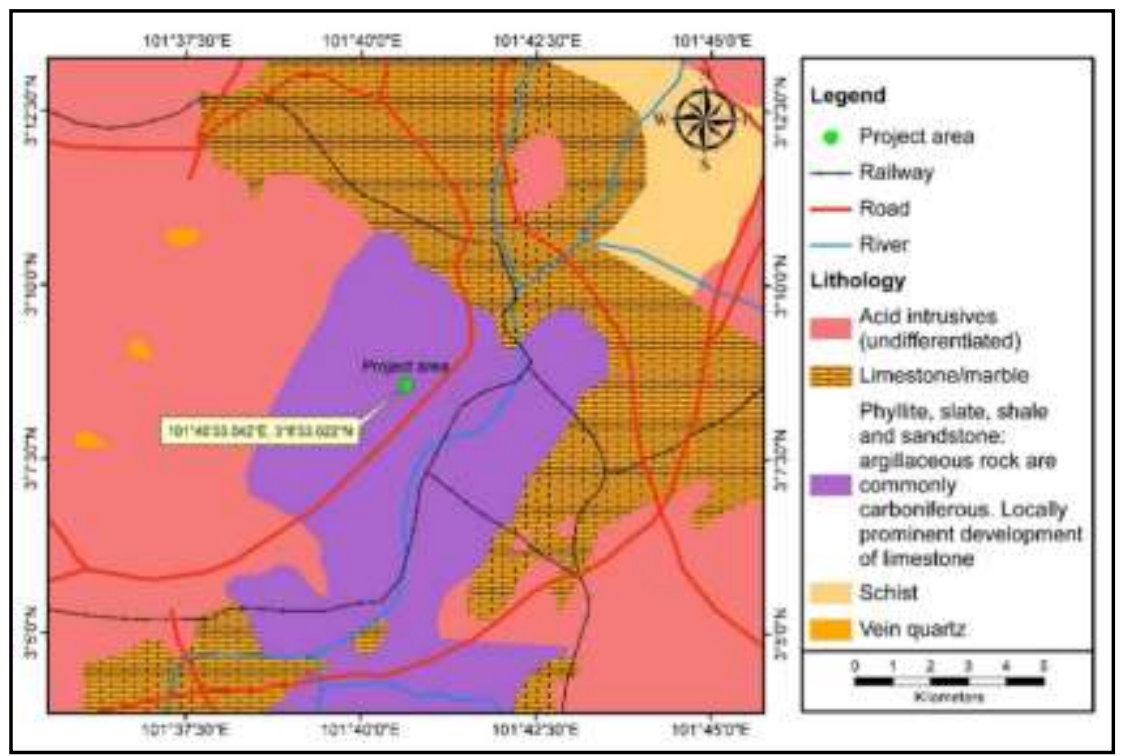

Fig. 2 - The types of rock units exist at the site and the surrounding area in Bukit Persekutuan, Kuala Lumpur 


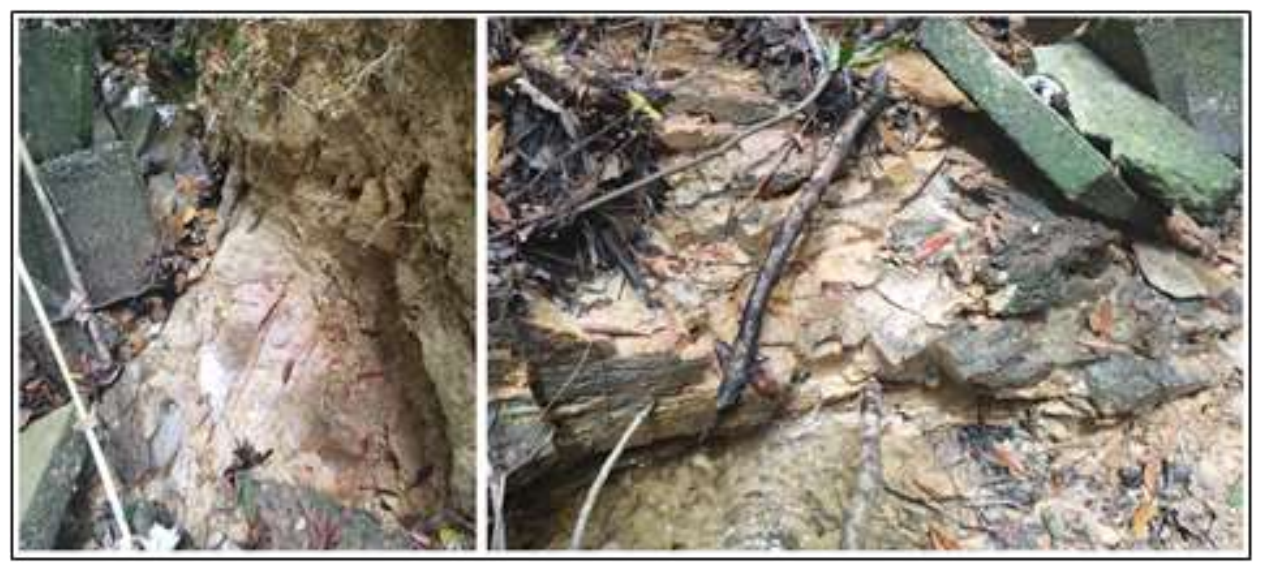

Fig. 3 - The foliated highly weathered phyllite exposed at drainage due to the water scouring erosion

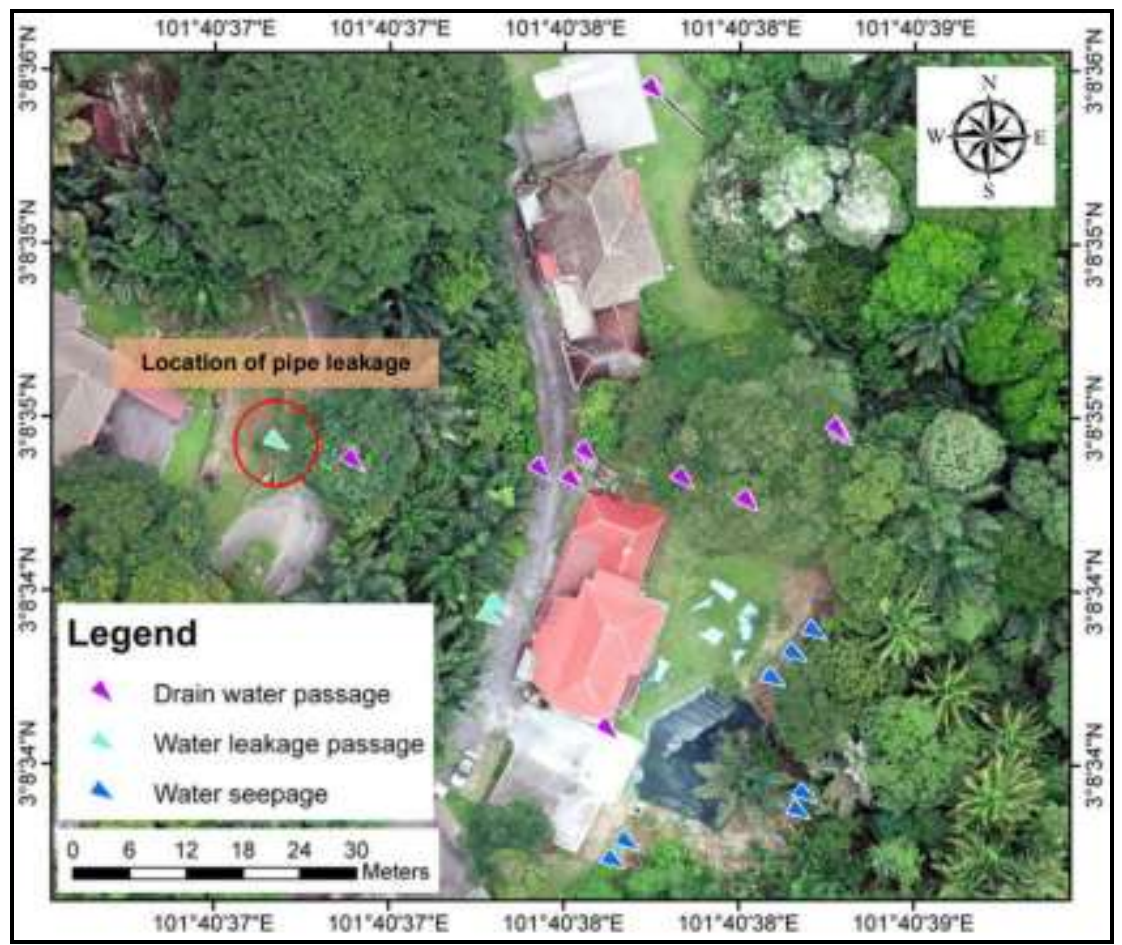

Fig. 4 - The location of water passages in the research area
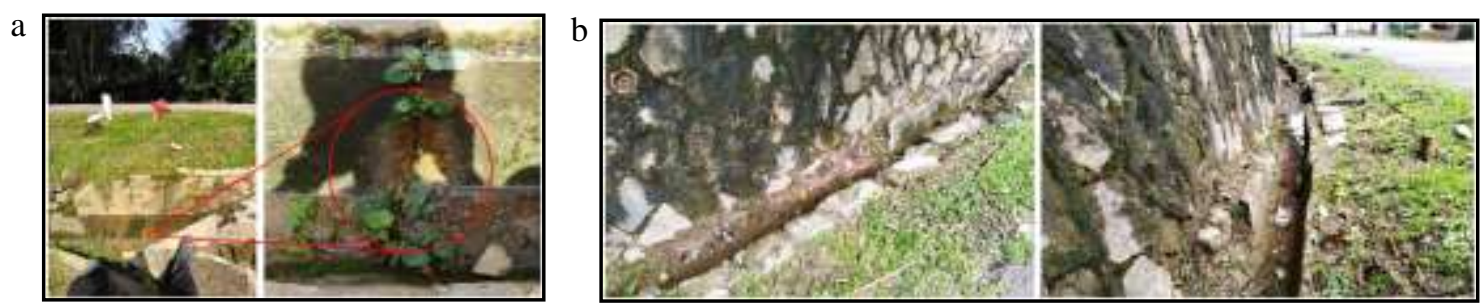

Fig. 5 - (a) Water flow due to the buried pipe leaks observed at the research area; (b) Continuous water flowing in the drain due to pipe leakage at the top of the slope near the landslide area 


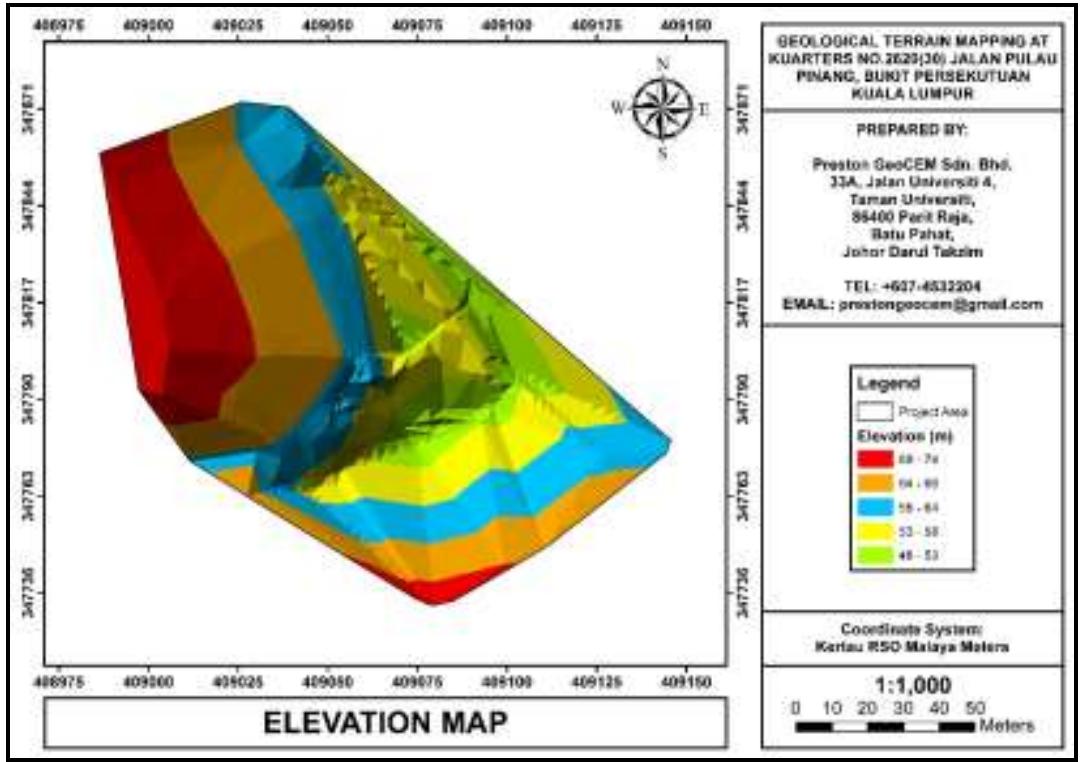

Fig. 6 - The elevation map of the research area

\section{The Geodynamic Features and Landslide Geohazard}

Field mapping identifies landslides events that occur in the project area. In Figure 7, the landslide size area of about $150 \mathrm{~m}^{2}$ and involves residual to completely weathered phyllite. The rotational failure of soil mass displaced the tree in an inclined state. The rotational failure landslide depicted the movement of soil mass on a concave slip plane. Figure 8 shows the water scouring erosion that occurs along the existing drainage. The water scouring erosion has been worsened due to the high intensity of rainfall. From field observation, the geometry and shape of the slope failure resemble much of a deep rotational landslide with a subcircular sliding plane and curved crown.

Figure 9 shows the tension cracks along the pavement edge, indicating side movement towards downslope. Figure 10 shows recent instability at the roadside slope where the existence of tension crack at the upper part of the natural slope and possible to contribute to the landslide event. Besides, at the Figure 10, it shows the geodynamic events at the site where crack features were present at the drain's sump and stone pitching wall. There was also slope displacement as an indication of localizing landslides. All the signs events as discussed above show high potential for the landslide. Thus, an instance preventive measure was needed to avoid a large-scale landslide.

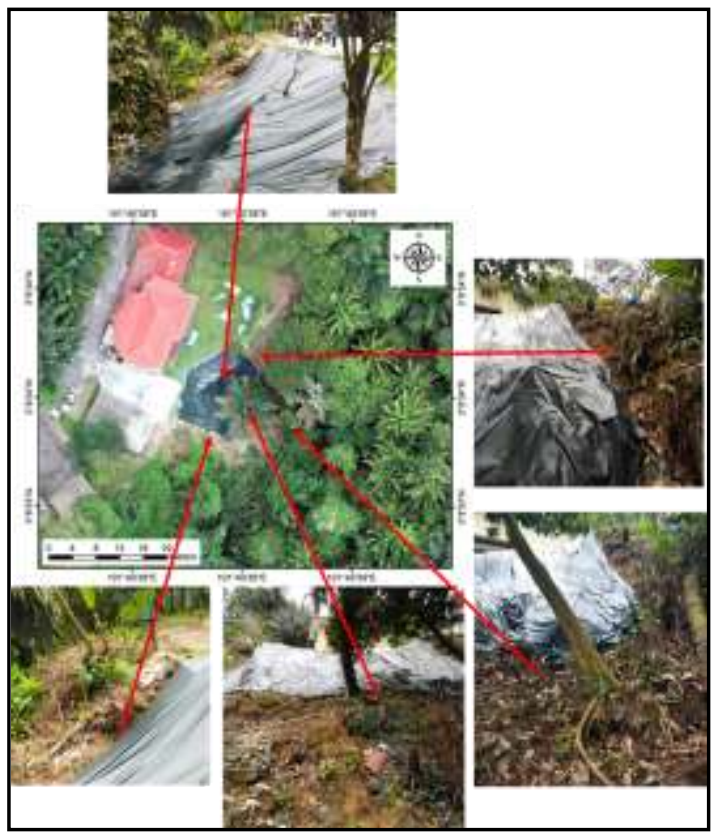

Fig. 7 - The rotational failure of soil mass movement at the site. The displacement of a tree in an inclined state, an indicator for slope movement 


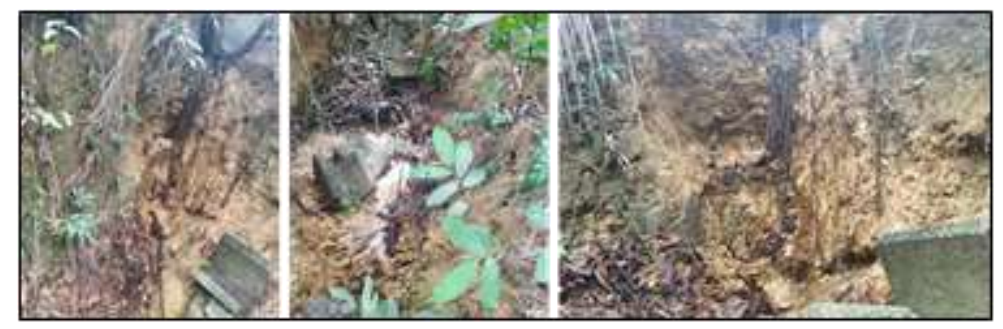

Fig. 8 - The water scouring occurs along the broken cascade drain. The water scouring causes the instability of the ground and could be triggered an enormous landslide

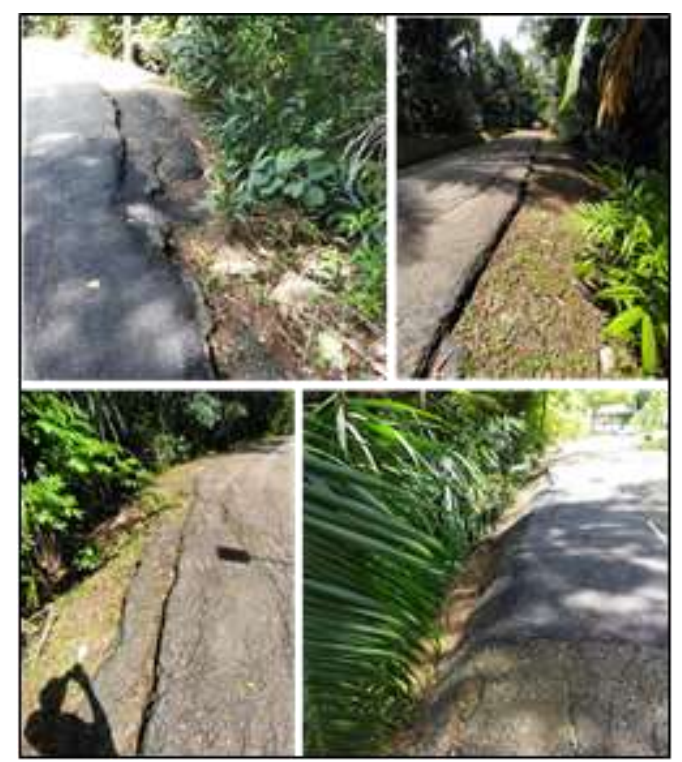

Fig. 9 - Some pavement distress indicates the slope movement resulting in the displacement of the pavement. The tension cracks appear along the road
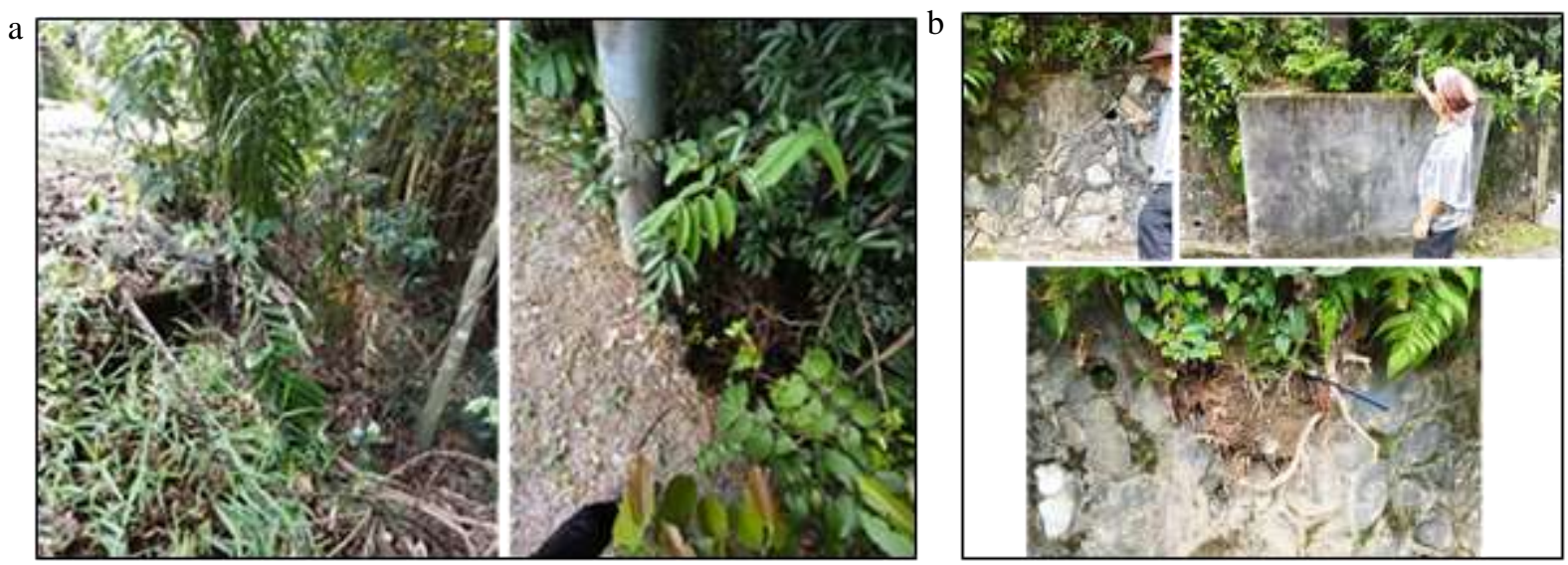

Fig. 10 - (a) The recent instability occurred at the roadside area where the existence of tension crack at the upper part of the natural slope can contribute to the landslide event; (b) The geodynamic events occurred at the site where the crack features at the drain's sump and stone pitching wall. There was also slope displacement as an indication of localizing landslides

\section{Geological Terrain Mapping and Analysis}

\subsection{Slope Gradient}

The slope gradient calculated from the topography survey plan is shown in Figure 11. The computer-generated slope gradient map shows that approximately $30.27 \%$ of the total site area has a slope gradient of less than $15^{\circ}$. The study also indicates that areas with a slope gradient of $16^{\circ}$ to $25^{\circ}$ comprise $38.87 \%$ of the total site area. Other than that, the areas with a slope gradient of $26^{\circ}$ to $35^{\circ}$ comprise approximately $23.54 \%$ of the total site area. In comparison, the areas with a slope gradient of more than $36^{\circ}$ comprise approximately $7.32 \%$ of the total site area. 


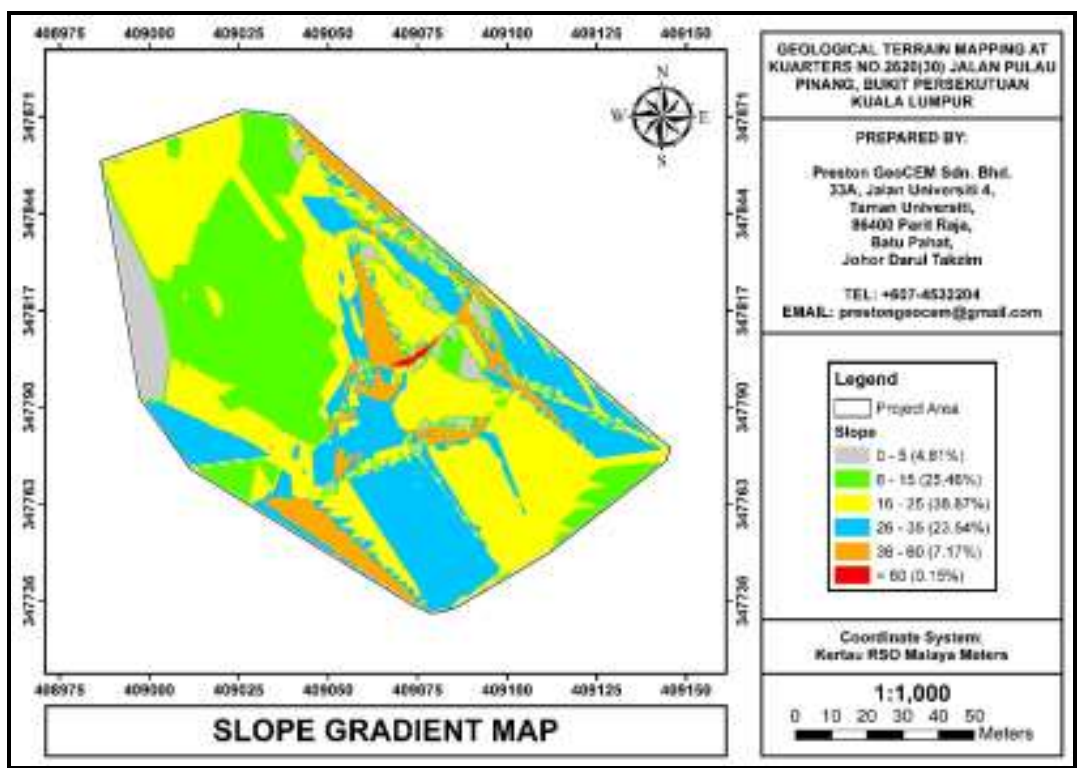

Fig. 11 - Slope gradient map produces for the research region analysis. The project site can be categories as a flat area

\subsection{Erosion and Instability}

The erosion and landslide failure affect the project site. There was one type of erosion: gully erosion with different degrees of severity. Other than erosion, some indicators of severe landslides were significantly depicted at the project site. The size ranged from $20-60 \mathrm{~m}$. Landslide mainly occurs at the slope with more than $25^{\circ}$ angle, especially at grade V-VI materials. The erosion and instability map are presented in Figure 12. The erosion and instability map shows that $79.11 \%$ of the project site's total area was not appreciable with erosion, while $8.58 \%$ of erosion area, $11.00 \%$ of instability area and $2.97 \%$ experienced landslide events.

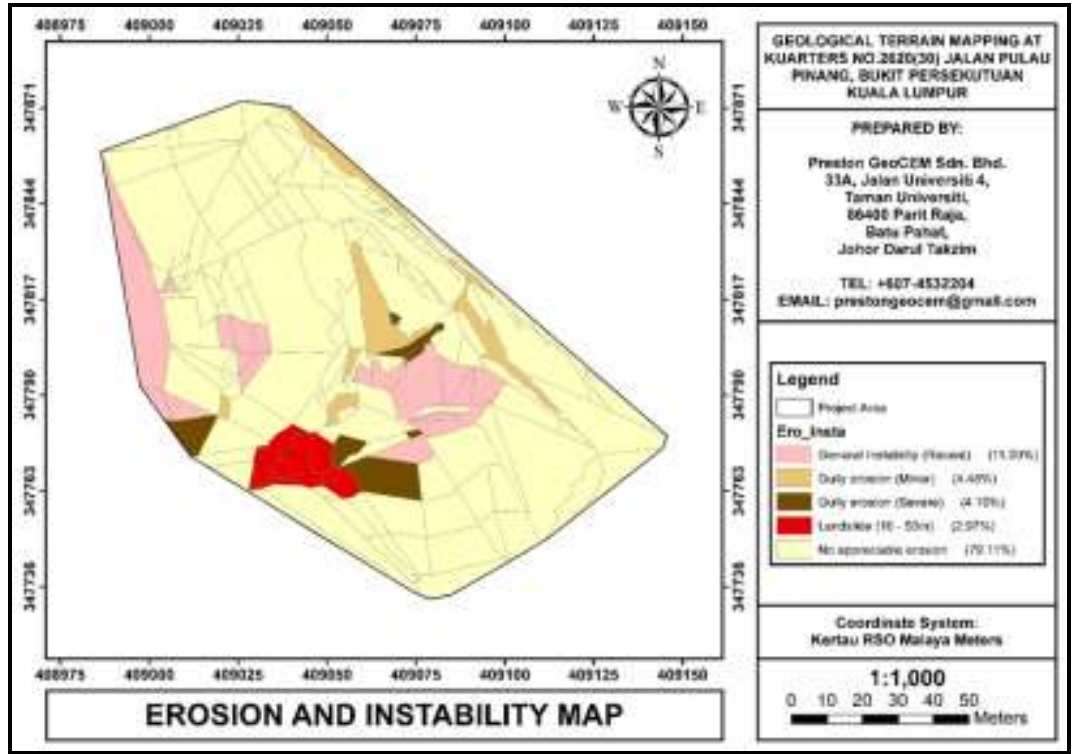

Fig. 12 - Erosion and instability map generated based on input from field mapping conducted previously at research area

\subsection{Terrain Classification}

The terrain classification map summarizes all findings from field mapping and GIS analysis at the project site. The terrain classification map compiled four parameters; slope gradient, terrain code, activity code, and erosion and instability. As suggested by Jabatan Mineral and Geosains Malaysia, each parameter was given a code, referred to in the Appendix section. The combination of four different information was used to produce a construction suitability map with different classes. The terrain classification map for the project site is presented in Figure 13. 


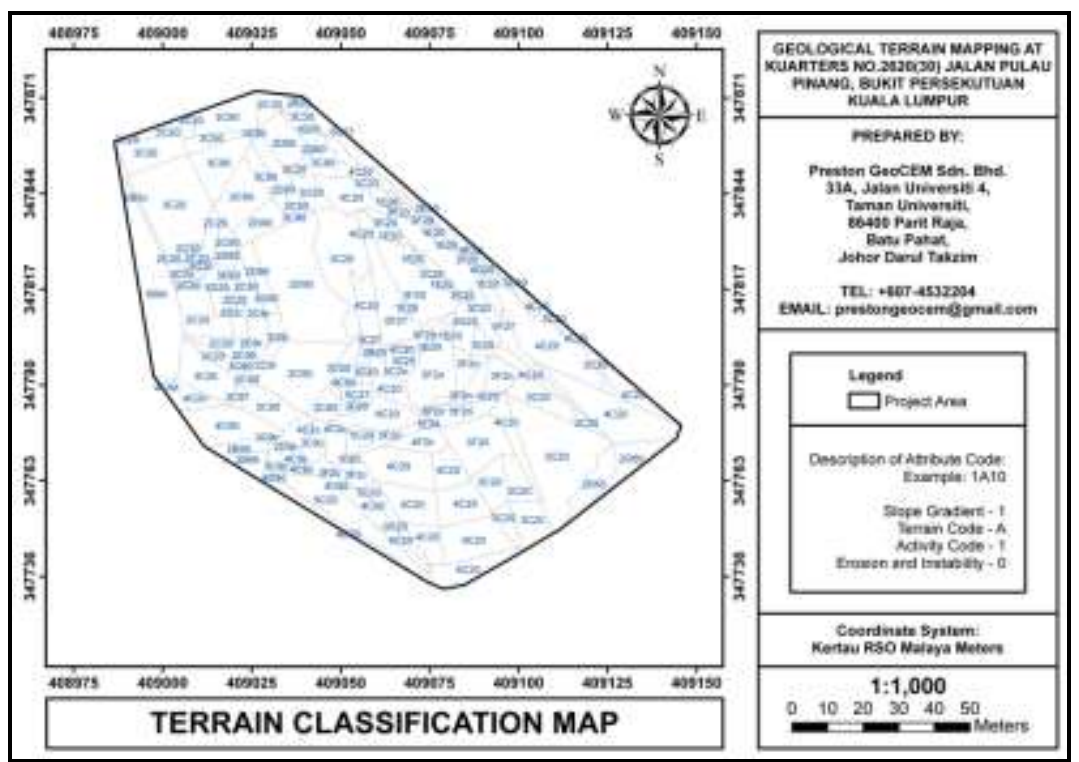

Fig. 13 - The terrain classification map at the project site

\subsection{Construction Suitability}

The construction suitability map was produced from the geological terrain classification map. The terrain classification attribute for regional studies is shown in the Appendix section. The map of construction of suitability map generated from terrain classification map is shown in Figure 7. It was estimated that almost 59.77\% of the total area in the project site was categorized as Class I \& II. These areas are usually flat and do not show any sign of slope instability and erosion. At the same time, almost $26.39 \%$ of project sites were classified as Class III. These areas were expected to have high to extreme geotechnical limitations and required intensive site investigation works. Significant slope instability and erosion were identified in these classes. The other $15.50 \%$ of the area was illustrated as a Class IV, and it was included extremely high geotechnical limitations and required very intensive site investigation works. Besides, Class IV was not suitable for any development purposes.

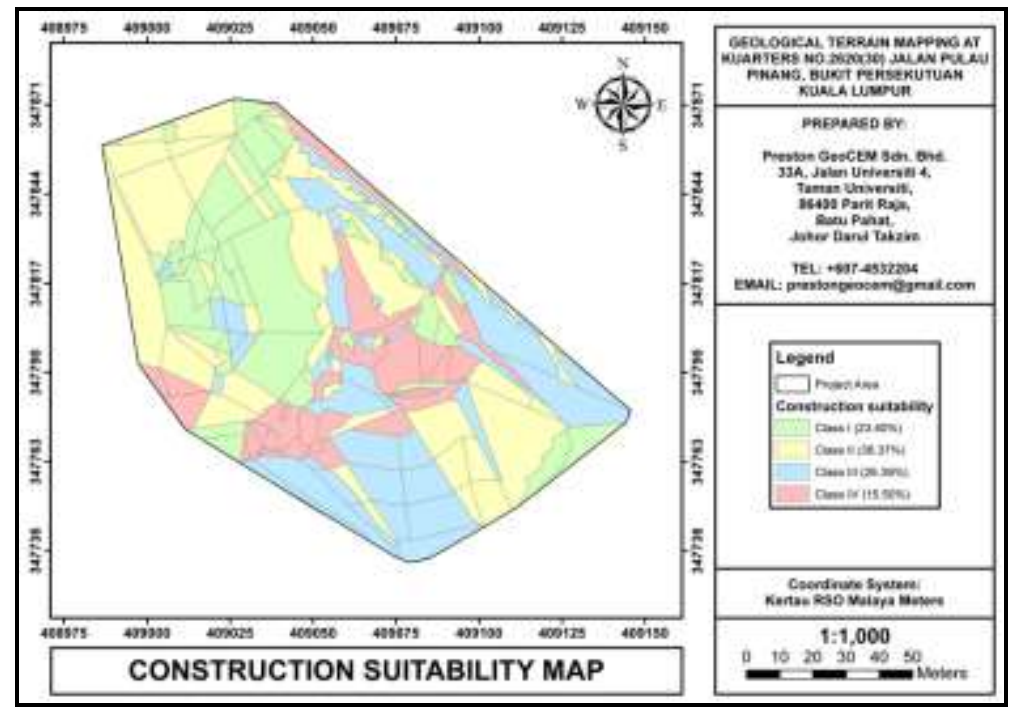

Fig. 14 - The distribution of classes in the project site based on various parameters

\section{Geotechnical Limitations and Considerations}

The terrain, geological materials, slope gradient, and instability influenced the project site's geotechnical limitations. The potential for slope failure increases with slope gradient; thus, steep areas are prone to landslides and erosion. The slope condition at the study area indicates that the possibility of failure thus needs further site investigation to obtain soil profile and soil strength. Thus, this study area should be treated with suitable mitigation methods. It was 
recommended that all the newly formed slope surfaces be protected to prevent erosion and potential slope failure. Proper slope protection, drainage system, maintenance, and monitoring programs should be implemented.

\section{Conclusion and Recommendations}

In conclusion, geological terrain mapping includes utilizing data retrieved from the field monitoring at the research area. Besides, it was derived from the drone photogrammetry processed images by developing an orthomosaic map of high-resolution imagery that can be applied to quantify accurate distances between verified geographic features. Each of the thematic maps produces capable of serving as significant guidance towards developing an area in the future.

The terrain classification and construction suitability maps were successfully applied following the geological terrain mapping guidelines from the Minerals and Geoscience Department Malaysia (JMG) and sectoral report volume 1 of National Slope Master Plan provided by slope engineering branch, JKR Malaysia.

From the research area, two types of slope instability encountered during field mapping were water scouring erosion and landslide. The slope instability occurs in a completely weathered phyllite rock mass, and it was attributed mainly to pipe water leakage and continuous water flow along with concrete and natural drainage. The sign of pavement distress and water pipe leakage at the top of the slope may endanger the slope stability. The water causes reduction of residual soil to completed weathered material rock mass strength as the soil slope forming material made it easier for the erosion process to occur.

Furthermore, a detailed geotechnical approach needs to be implemented, such as soil investigation involving soil sampling, logging and testing, and detailed slope stability assessment for the site-specific project. The following general mitigations were recommended in this research area. The erosion should be treated with suitable methods, such as turfing to prevent further erosion and toe undercutting on the slope. This slope section should also be equipped with a berm and cut-off drains to divert water runoff flows away off the slope. An appropriate slope reinforcement method should apply to avoid the occurrence of new slope failure. In this case, the slope angle should be gentler, especially at the slope with a low height. Besides that, a professional engineer can also increase slope safety using soil nails with a proper geotechnical design.

\section{Acknowledgement}

The authors would like to acknowledge the Geoscience Department, Faculty of Earth Science, University Malaysia Kelantan, Jeli, Kelantan, Faculty of Civil Engineering and Built Environment, Universiti Tun Hussein Onn of Malaysia, Parit Raja, Johor, Preston GeoCEM Sdn Bhd and Department of Survey and Mapping Malaysia, Wisma JUPEM, Jalan Sultan Yahya Petra, Kuala Lumpur.

\section{References}

[1] Sarkar, A., \& Patel, P. P. (2012). Terrain classification of the dulung drainage basin. Indian Journal of Spatial Science, 3(1), 1-8

[2] Abd Manap, M., Ramli, M. F., Sulaiman, W. N. A., \& Surip, N. (2010). Application of remote sensing in the identification of the geological terrain features in Cameron Highlands, Malaysia. Sains Malaysiana, 39(1), 1-11

[3] Mineral and Geoscience Department Malaysia (2010). Geological Terrain Mapping Guidelines (JMG.GP.06)

[4] Slope Engineering Branch, Jabatan Kerja Raya Malaysia (2009). National Slope Master Plan 2009-2023

[5] Slope Engineering Branch, Jabatan Kerja Raya Malaysia (2009). Sectoral Report - Volume 1 (s), National Slope Master Plan 2009-2023

[6] Jabatan Perancangan Bandar dan Desa Semenanjung Malaysia, (2009). Garis Panduan Perancangan Pembangunan di Kawasan Bukit dan Tanah Tinggi

[7] Mohamad, Z., \& Sum, C. W. (2003). Geological terrain mapping in Cameron Highland district, Pahang

[8] Choubey, V., \& Litoria, P. (1990). Terrain classification and land hazard mapping in Kalsi-Chakrata area (Garhwal Himalaya), India. ITC Journal, 1, 65-68

[9] Khawlie, M. R., \& A'war, R. (1988). Terrain analysis for development studies: Typical mountainous area along the Eastern Mediterranean coast-Lebanon. Bulletin of the International Association of Engineering GeologyBulletin de l'Association Internationale de Géologie de l'Ingénieur, 38(1), 95-104

[10] Vold, T. E. R. J. E. (1982). Terrain analysis for transportation systems in British Columbia. Transportation Research Record, 892, 46-49

[11] ISRM (1981), Rock Characterization, Testing and Monitoring, ET Brown (ed.), Pergamon Press, Oxford 